\title{
Free amino acid content in infant formulas
}

\author{
Alison K. Ventura \\ Monell Chemical Senses Center, Philadelphia, Pennsylvania, USA \\ Ana San Gabriel and Mariko Hirota \\ Institute of Life Sciences, Physiology and Nutrition Group, \\ Ajinomoto Company, Inc., Kawasaki-shi, Japan, and \\ Julie A. Mennella \\ Monell Chemical Senses Center, Philadelphia, Pennsylvania, USA
}

\begin{abstract}
Purpose - Infant formula is the sole nutrition and food source for many infants. Information on the free amino acid (FAA) content of formulas, particularly those that are protein hydrolysate based, is limited, despite emerging evidence for the role of FAAs in regulating eating behaviour. The purpose of this paper is to measure levels of essential, semi-essential, and nonessential FAAs in commercially available infant formulas to provide a foundation for future research examining the influence of FAAs on infant development.

Design/methodology/approach - Using an automatic amino acid analyzer, we measured the concentrations of FAAs in four types of formula: two cow milk (CMF); three soy protein (SPF); and three protein hydrolysate (PHF), one of which was a partial hydrolysate (pPHF) and two of which were extensive hydrolysate (ePHF).

Findings - It was found that the amount and number of FAAs varied significantly across formula types: for $\mathrm{CMF}$, total FAAs ranged from $523-864 \mu \mathrm{mol} / \mathrm{L}$, with taurine being the most prominent; $\mathrm{SPF}$, 1933-2450, methionine; pPHF, 2329, taurine; and ePHF, 80375-85445, leucine. ePHF had the highest levels and the most diversified profiles of FAAs.

Research limitations/implications - Striking discrepancies exist for FAA profiles of infant formulas. Comparison of these data to published psychophysical data on the taste qualities of individual FAAs provides insights into the unique flavor profiles of infant formulas. Overall, the data from this study provide a necessary foundation for future research examining the influence of FAAs in formulas on infant growth and development.

Originality/value - Published data on the FAA content of PHF is limited, despite their increased availability and use. This research is the first to report the FAA content of partial and extensive PHF, and to compare these values to $\mathrm{CMF}$ and SPF.
\end{abstract}

Keywords Free amino acids, Infant formulas, Protein hydrolysate formula

Paper type Research paper

The project described was supported by awards R01HD37119, R01HD072307-01 and F32 HD063343-01A1 from the Eunice Kennedy Shriver National Institute of Child Health and Human Development. Dr Ventura was a postdoctoral trainee supported by NIH grant T32-DC00014. The content is solely the responsibility of the authors and does not necessarily represent the official views of the Eunice Kennedy Shriver National Institute of Child Health and Human Development or the National Institutes of Health. The authors would also like to thank Dr Toshimi Mizukoshi for his help and critical advice in the interpretation of the data analysis. pp. $271-278$ 
NFS

42,4

272

\section{Introduction}

During early life, the protein in human milk and infant formulas supports infant growth, immune function, and behavioral development by supplying nitrogen and essential and semi-essential amino acids (Dewey et al., 1996). Because of rapid rates of growth during infancy, and because the metabolic pathways needed to create semi-essential amino acids are not fully developed (Imura and Okada, 1998), the protein content and levels of the nine essential and four semi-essential amino acids for infant formulas are specified by the World Health Organization (WHO) (FAO/WHO, 2007).

Current formulas for term infants vary in protein source and/or degree of protein hydrolysis (see American Academy of Pediatrics Committee on Nutrition (2000), Koletzko et al. (2005) for review). Cow milk formula (CMF), which accounted for 76 percent of all US infant formula sales in 2000 (ERS/USDA, 2005), has a protein source that includes casein or whey proteins. Soy protein formula (SPF) contains soy protein isolate, usually intact but sometimes partially digested. Less prevalent is extensive protein hydrolysate formula (ePHF), which is typically fed to infants who have cow milk protein allergy or intolerance to intact protein (American Academy of Pediatrics Committee on Nutrition, 2000). The milk proteins in ePHF are treated with enzymes to break down the protein structure to reduce allergenicity and facilitate digestion (Cook and Sarett, 1982; Lee, 1992). Partial protein hydrolysate formulas (pPHF) are also available, containing a combination of intact and partially digested proteins.

Differences in protein source, processing, and degree of hydrolysis create large differences in the non-protein nitrogen content of formulas (Cook and Sarett, 1982; Lee, 1992), which includes free amino acids (FAAs), urea, small peptides, and any other nitrogen-containing compounds that are not bound to intact proteins (Rudloff and Kunz, 1997). Despite the significant contribution of non-protein nitrogen to the total nitrogen content of infant formulas (Donovan and Lonnerdal, 1989), WHO standards do not specify FAA content in infant formulas (FAO/WHO, 2007; Koletzko et al., 2005). Further, the exact levels of FAAs present in infant formulas are not typically provided on manufacturers' web sites and research documenting the FAA content of CMF and SPF is limited (Agostoni et al.,2000; Caja et al.,2006; Chuang et al., 2005; Ferreira, 2003; Yeung et al., 2006; Zunin and Evangelisti, 1999). Additionally, no studies have described the FAA content of pPHFs or ePHFs.

The paucity of information on the FAAs in infant formulas, particularly PHF, is significant for two reasons. First, the consumption of both pPHF and ePHF has been on the rise among healthy formula-fed infants. Second, formula-fed infants are not a homogeneous group. For example, we recently reported that, when compared to breastfed infants, CMF-fed infants weight gain was accelerated, whereas the weight gain of ePHF-fed infants was normative (Mennella et al., 2011). The more normative growth may be attributed to the finding that ePHF-fed infants consumed less formula to satiation during monthly laboratory-based, infant-led feeding sessions than did CMF-fed infants.

Based on these data, we hypothesize that higher levels of FAAs in ePHF compared to $\mathrm{CMF}$ contribute, in part, to these differences in satiation and growth. However, this hypothesis, and others like it, cannot be tested until data on the exact levels of FAA in formulas are available. To this end, we measured levels of essential, semi-essential, and nonessential FAAs in commercially available infant formulas to provide a foundation for future research examining the influence of FAAs on infant development. 


\section{Materials and methods}

A representative sample of the formulas most commonly consumed by US infants (ERS/USDA, 2005) was selected at random from a supermarket in Philadelphia (PA, USA). To this end, eight different formulas were studied: two CMF, three SPF, one pPHF, and two ePHF (Table I). We chose the liquid-ready-to-feed versions, rather than powdered or liquid concentrate, to minimize errors in preparation (FAO/WHO, 2007). We also analyzed two powdered versions (CMF-1, PHF-1) to compare powdered versus liquid-ready-to-feed formulations.

For each formula, $20 \mathrm{~mL}$ was deproteinized with $10 \mathrm{~mL}$ sulfosalicylic acid ( 6 percent), mixed on vortex type mixer, and centrifuged immediately $\left(4^{\circ} \mathrm{C}, 15 \mathrm{~min}, 1,200 \mathrm{~g}\right)$. The supernatant was purified with a $0.45 \mu \mathrm{m}$ filter, and molecules $>10 \mathrm{kDa}$ were removed with an Amicon ${ }^{\circledR}$ Ultra centrifugal filter (Millipore, Tokyo, Japan). We measured amino acid concentrations with an automatic amino acid analyzer (model L-8900; Hitachi, Tokyo, Japan) that separates amino acids by cation-exchange chromatography. The analyzer system has a high-reproducibility retention time with coefficient of variation (CV) 0.3 percent (Arg), peak area with CV 1.0 percent (Gly, His), and limit of detection (LOD) of 3 pmol (signal-to-noise ratio (S:N) $=2$; Asp). Reproducibility was verified by measurements of standard preparations.

Each amino acid was detected spectrophotometrically after postcolumn reaction with ninhydrin reagent (Noguchi et al., 2006). We diluted SPF-3 (six-fold) and ePHF-1 (7.5-fold) because initial analyses revealed that amino acid levels were out of range. Samples were analyzed in duplicate; data were adjusted for dilution factor (if applicable) and are presented as average micromoles per liter. Amino acid standards were intercalated with each sample to ensure reproducibility $\geq 98$ percent or $\mathrm{CV}<2$ percent. LOD varied from 2 to $10 \mu \mathrm{mol} / \mathrm{L}$ and was specific to each amino acid. Values $<$ three-fold the S:N were considered to be in the LOD.

\section{Results and discussion}

Table I presents FAA levels for each formula. ePHF had the highest levels of FAAs, averaging 120-fold higher than CMF, 39-fold higher than SPF, and 36-fold higher than pPHF. Many FAAs were undetectable or present at the LOD (i.e. present in trace amounts), meaning these amino acids are present only within intact proteins in these formulas. In contrast, all FAAs were detected in $\mathrm{PHF}$ (with the exception of glutamine in ePHF-1).

ePHF was most abundant in free leucine (14-15 percent), glutamic acid (9-10 percent), lysine (8-10 percent), and valine (9 percent), which accounted for approximately 42 percent of total FAA content. ePHF also differed within formula type: ePHF-2 contained more FAAs than did ePHF-1 (85,445 versus $80,375 \mu \mathrm{mol} / \mathrm{L}$ ), almost two-fold the proline of ePHF-1, and a small amount of glutamine, versus none in ePHF-1. Levels of FAAs were substantially lower in $\mathrm{pPHF}$ than in $\mathrm{ePHF}$, and some amino acids (isoleucine, leucine, valine, cystine, glutamine) found at high levels in ePHF were not detectable in $\mathrm{pPHF}$.

Overall, the total FAA content for SPF, ranging from 1,933 to 2,450 $\mu \mathrm{mol} / \mathrm{L}$, was lower than for ePHF. Only seven to 12 of the FAAs found in SPF exceeded the LOD in free form. SPF was most abundant in methionine, which contributed 65-75 percent of FAA content. Taurine was the next most abundant, contributing 21-22 percent of FAA content. The other FAAs each contributed $<2$ percent of the FAA content.
FAA content in infant formulas

273 
NFS

42,4

274

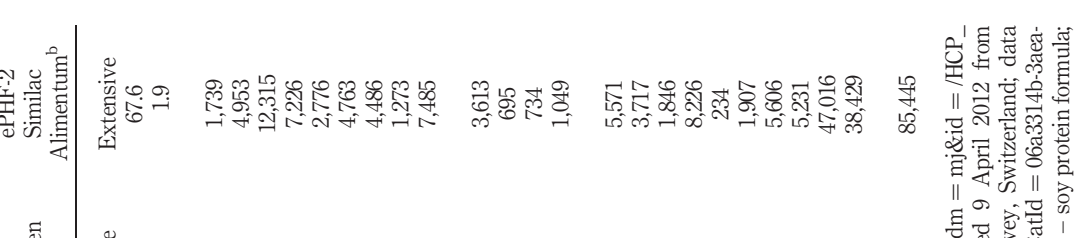

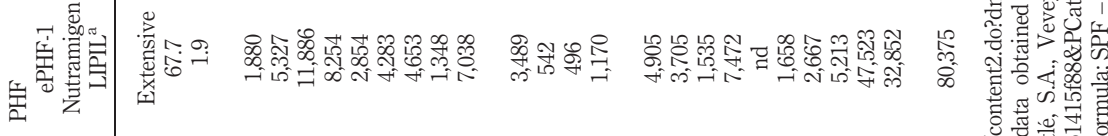

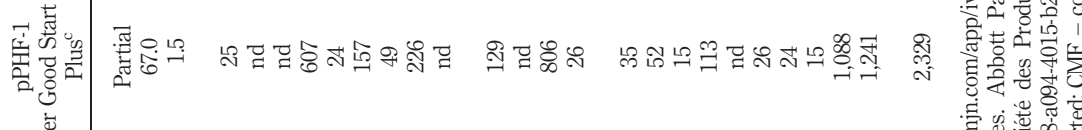

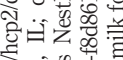

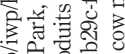

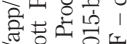

矛

总

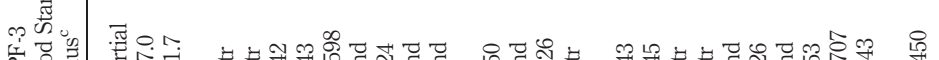

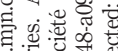

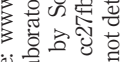
类高要

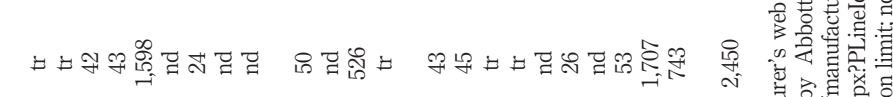

这

की

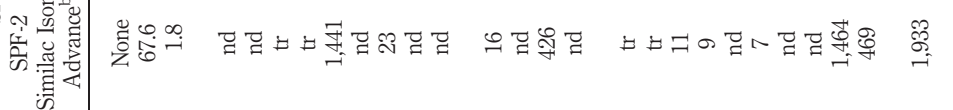

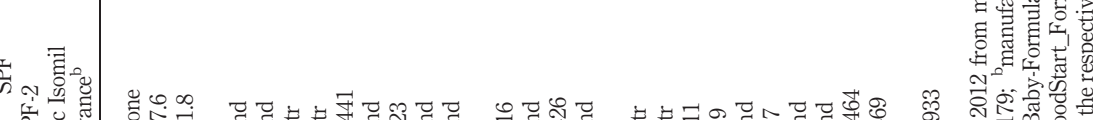

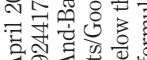
羊定

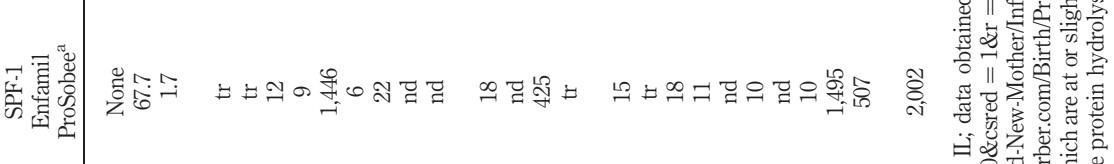

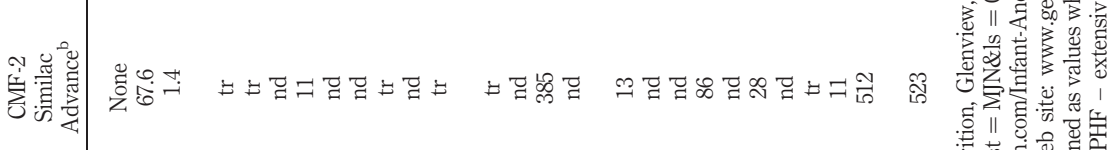

$\sum^{5}$

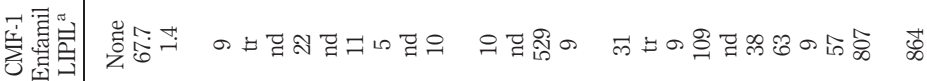
3

Table I.

FAA content $(\mu \mathrm{mol} / \mathrm{L})$ of different types of infant formulas 
The total FAA content for CMF (523-864 $\mu \mathrm{mol} / \mathrm{L}$ ) was considerably lower than for SPF and PHF. While the most abundant FAAs in CMF were taurine (61-74 percent) and glutamic acid (13-17 percent), the two CMFs differed most in proline content: 7 percent in CMF-1 versus none in CMF-2. CMF-1 also contained 1.7-fold the amount of FAAs found in CMF-2.

Comparison of powdered and liquid-ready-to-feed versions of CMF-1 and ePHF-1 showed little variation (data not shown). For example, CMF-1 as powder contained $125 \mu \mathrm{mol} / \mathrm{L}$ free glutamate, versus $109 \mu \mathrm{mol} / \mathrm{L}$ in the liquid-ready-to-feed version. Similarly, ePHF-1 as powder contained 7,238 $\mu \mathrm{mol} / \mathrm{L}$ free glutamate, versus 7,472 $\mu \mathrm{mol} / \mathrm{L}$ in the liquid-ready-to-feed version. The $\mathrm{CV}$ was 1.7 between the CMF-1 formulations and 0.8 between the ePHF- 1 formulations.

It remains unknown why the levels of FAAs are so high in some formulas and what impact FAA content may have on infant development (see commentary in Hernell and Lonnerdal (2003)). In the present study, we found that total levels of FAAs in ePHF were substantially higher than in human breast milk (3,019 $\mu \mathrm{mol} / \mathrm{L}$ (Agostoni et al., 2000)). In contrast, FAA levels in CMF or SPF were two- to five-fold lower than in breast milk (Agostoni et al., 2000). Several studies have documented that infants who feed ePHF have much higher serum FAAs than do infants fed breast milk or non-hydrolyzed formulas (Giovannini et al., 1994; Hernell and Lonnerdal, 2003; Rigo et al., 1995), the consequence of which is still unclear. The effects, if any, that the relative and absolute levels of FAAs in breast milk or formulas have on the establishment of long-term flavor and food preferences and understanding the impact of their effects on infant feeding, growth, and development should be a priority for future research.

Infants can detect flavor differences among various types of formulas and grow to prefer the brand that they experience early in life (Mennella and Beauchamp, 2005). Because these flavors are complex, psychophysical data for formulas will not provide information on how their varying FAA levels contribute to overall flavor. As a preliminary examination of the potential relation between formula feeding and flavor preferences, we compared published psychophysical data on the taste qualities of individual FAAs (Schiffman et al., 1979; Schiffman and Dackis, 1975) with the FAA profiles of individual formulas from the present study (Table II). For each formula under study, FAAs that comprised greater than 1 percent of the total FAA content were ranked based on the amount present in the formula $(1=$ highest amount).

By combining the findings of the present study with the information provided by Schiffman and Dackis (1975), one may predict the impact FAA content on the flavor of infant formula. For example, sensory panel work has shown that SPF tastes more sweet, sour, and bitter than CMF (Cook and Sarett, 1982). SPF is enriched with both taurine and methionine, as reflected in the relative abundance of these two amino acids in the soy formulas analyzed in the present study. Methionine has been reported to taste "repulsive, metallic, minerally [.. . ] bitter" (Schiffman and Dackis, 1975), which is may be one contributor to the bitterness of SPF. Sweet flavors of SPF may come from, in part, the relatively higher levels of taurine (Schiffman and Dackis, 1975).

The savory, sour, and bitter flavors of ePHF may be attributable to the high levels of glutamic acid (meaty or savory), valine (slightly bitter with sour and sweet aspects), and lysine (salty and bitter) (Schiffman and Dackis, 1975). Additionally, differences in FAA profiles between ePHFs may underlie reports that ePHF-2 is sweeter than ePHF-1 (Mennella and Beauchamp, 2005): ePHF-2 contains almost twice as much proline,
FAA content in infant formulas

275 


\begin{tabular}{l} 
NFS \\
42,4 \\
$\mathbf{2 7 6}$ \\
\hline
\end{tabular}

Table II.

Psychophysical taste qualities of FAAs ${ }^{\mathrm{a}}$ and FAA ranking ${ }^{\mathrm{b}}$ according to amount detected in a variety of infant formulas

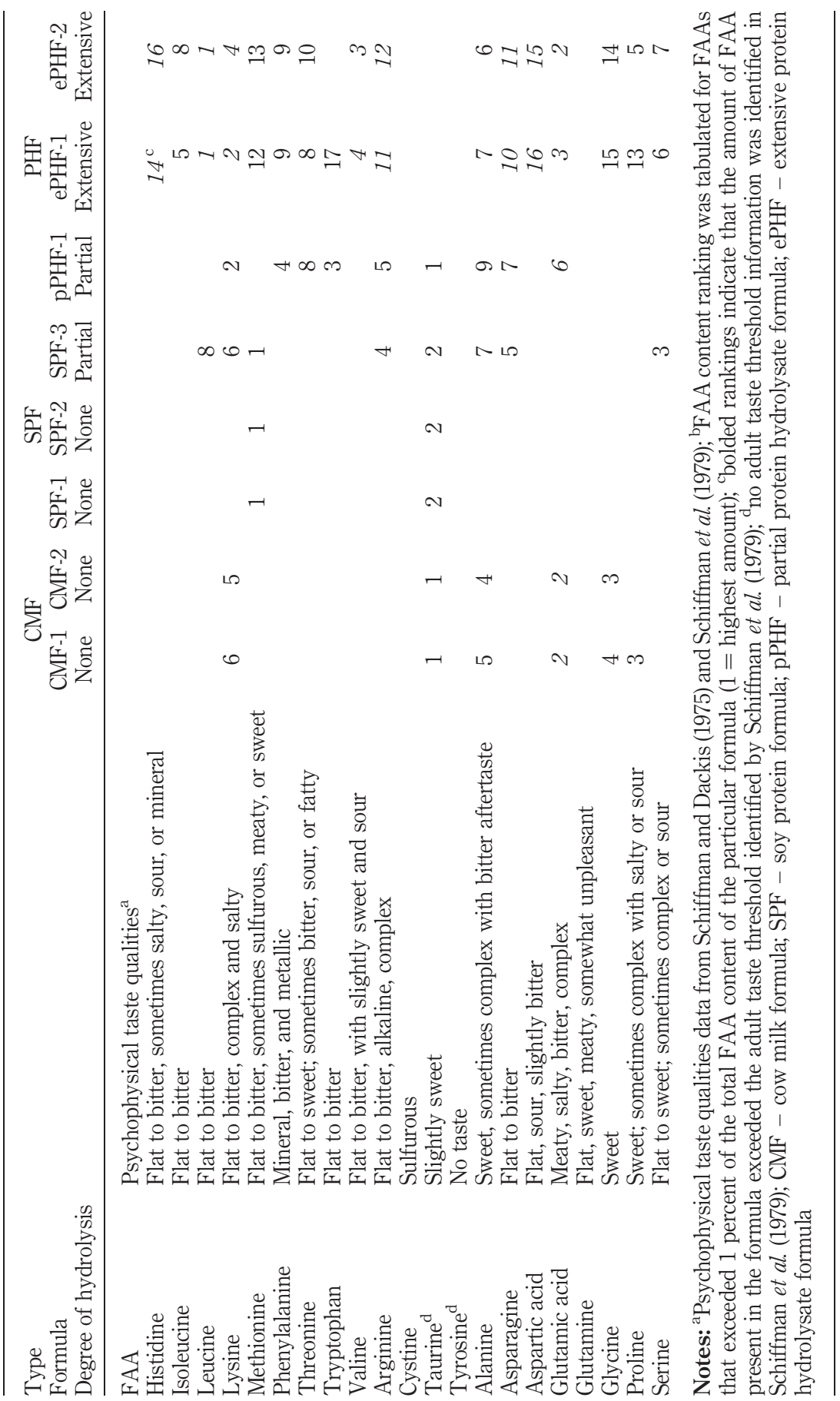


a sweet tasting amino acid, as ePHF-1. However, it is also important to note that the difference in sweetness may also be due to differences in carbohydrate source, as ePHF-2 contains sucrose and corn maltodextrin while ePHF-1 contains corn syrup solids and modified corn starches. Overall, the higher levels of FAAs in ePHF may create a more powerful flavor experience compared with other formula types and thus underlie strong and distinctive bitter, sour, and savory taste characteristics of ePHF.

\section{Conclusions}

Striking differences exist both among and within different types of infant formulas in total amounts and numbers of FAAs. Differences between CMF and SPF centered on taurine and methionine, as previously reported (Agostoni et al., 2000), whereas differences among non-hydrolyzed (CMF, SPF), partially hydrolyzed (pPHF), and extensively hydrolyzed (ePHF) formulas were considerable. These findings provide insights into the unique flavor profiles of infant formulas and a foundation for examining the mechanisms underlying the differential impact of infant formulas on infant satiation and growth.

\section{References}

Agostoni, C., Carratu, B., Boniglia, C., Riva, E. and Sanzini, E. (2000), "Free amino acid content in standard infant formulas: comparison with human milk", Lournal of the American College of Nutrition, Vol. 19 No. 4, pp. 434-8.

American Academy of Pediatrics Committee on Nutrition (2000), "Hypoallergenic infant formulas", Pediatrics, Vol. 106 No. 2 Part 1, pp. 346-9.

Caja, M.M., Blanch, G.P. and Calvo, M.M. (2006), "Composition of free amino acids in infant formulas”, Milchwissenschaft, Vol. 61 No. 4, pp. 360-2.

Chuang, C.K., Lin, S.P., Lee, H.C., Wang, T.J., Shih, Y.S., Huang, F.Y. and Yeung, C.Y. (2005), "Free amino acids in full-term and pre-term human milk and infant formula", Iournal of Pediatric Gasteroenterology and Nutrition, Vol. 40 No. 4, pp. 496-500.

Cook, D.A. and Sarett, H.P. (1982), Design of Infant Formulas for Meeting Normal and Special Need. Pediatric Nutrition: Infant Feeding, Deficiencies, Disease, MarcelDekker, Inc., New York, NY.

Dewey, K.G., Beaton, G., Fjeld, C., Lonnerdal, B. and Reeds, P. (1996), "Protein requirements of infants and children", European Journal of Clinical Nutrition, Vol. 50, pp. S119-47, discussion S147-50 (supplement 1).

Donovan, S.M. and Lonnerdal, B. (1989), "Non-protein nitrogen and true protein in infant formulas", Acta Paediatrica Scandinavica, Vol. 78 No. 4, pp. 497-504.

ERS/USDA (2005), "Infant formula trends", WIC and the Retail Price of Infant Formula, USDA FANRR-39.

FAO/WHO (2007), Codex Alimentarius: Standard for Infant Formula and Formulas for Special Medical Purposes Intended for Infants, Food and Agriculture Organization of the United Nations, World Health Organization CODEX STAN 72-1981.

Ferreira, I.M. (2003), "Quantification of non-protein nitrogen components of infant formulae and follow-up milks: comparison with cows' and human milk", British Journal of Nutrition, Vol. 90 No. 1, pp. 127-33.

Giovannini, M., Agostoni, C., Fiocchi, A., Bellu, R., Trojan, S. and Riva, E. (1994), “Antigen-reduced infant formulas versus human milk: growth and metabolic parameters in the first 6 months of life", Journal of the American College of Nutrition, Vol. 13 No. 4, pp. 357-63.

FAA content in infant formulas 
NFS

42,4

\section{8}

Hernell, O. and Lonnerdal, B. (2003), "Nutritional evaluation of protein hydrolysate formulas in healthy term infants: plasma amino acids, hematology, and trace elements", American Iournal of Clinical Nutrition, Vol. 78 No. 2, pp. 296-301.

Imura, K. and Okada, A. (1998), "Amino acid metabolism in pediatric patients”, Nutrition, Vol. 14 No. 1, pp. 143-8.

Koletzko, B., Baker, S., Cleghorn, G., Neto, U.F., Gopalan, S., Hernell, O., Hock, Q.S., Jirapinyo, P., Lonnerdal, B., Pencharz, P., Pzyrembel, H., Ramirez-Mayans, J., Shamir, R., Turck, D., Yamashiro, Y. and Zong-Yi, D. (2005), "Global standard for the composition of infant formula: recommendations of an ESPGHAN coordinated international expert group", Lournal of Pediatric Gasteroenterologv and Nutrition, Vol. 41 No. 5, pp. 584-99.

Lee, Y.H. (1992), "Food-processing approaches to altering allergenic potential of milk-based formula”, Lournal of Pediatrics, Vol. 121 No. 5 Pt 2, pp. S47-S50.

Mennella, J.A. and Beauchamp, G.K. (2005), "Understanding the origin of flavor preferences", Chemical Senses, Vol. 30, Supplement 1, pp. i242-i243.

Mennella, J.A., Ventura, A.K. and Beauchamp, G.K. (2011), "Differential growth patterns among healthy infants fed protein hydrolysate or cow-milk formulas", Pediatrics, Vol. 127 No. 1, pp. 110-18.

Noguchi, Y., Zhang, Q.W., Sugimoto, T., Furuhata, Y., Sakai, R., Mori, M., Takahashi, M. and Kimura, T. (2006), "Network analysis of plasma and tissue amino acids and the generation of an amino index for potential diagnostic use", American Iournal of Clinical Nutrition, Vol. 83 No. 2, pp. 513S-19S.

Rigo, J., Salle, B.L., Picaud, J.C., Putet, G. and Senterre, J. (1995), "Nutritional evaluation of protein hydrolysate formulas", European Journal of Clinical Nutrition, Vol. 49, Supplement 1, pp. S26-S38.

Rudloff, S. and Kunz, C. (1997), "Protein and non-protein nitrogen components in human milk, bovine milk, and infant formula: quantitative and qualitative aspects in infant nutrition", Lournal of Pediatric Gasteroenterology and Nutrition, Vol. 24 No. 3, pp. 328-44.

Schiffman, S.S. and Dackis, C. (1975), "Taste of nutrients: amino acids, vitamins and fatty acids", Perception \& Psychophvsics, Vol. 17 No. 2, pp. 140-6.

Schiffman, S.S., Hornack, K. and Reilly, D. (1979), "Increased taste thresholds of amino acids with age", American Iournal of Clinical Nutrition, Vol. 32 No. 8, pp. 1622-7.

Yeung, C.Y., Lee, H.C., Lin, S.P., Yang, Y.C., Huang, F.Y. and Chuang, C.K. (2006), "Negative effect of heat sterilization on the free amino acid concentrations in infant formula", Eurobean Iournal of Clinical Nutrition, Vol. 60 No. 1, pp. 136-41.

Zunin, P. and Evangelisti, F. (1999), "Determination of free amino acids in infant formulas", International Dairv Iournal, Vol. 9 No. 9, pp. 653-6.

\section{About the authors}

Dr Alison K. Ventura is a Postdoctoral Fellow at the Monell Chemical Senses Center, Philadelphia, USA.

Dr Ana San Gabriel is a Senior Researcher in the Physiology and Nutrition Group at the Institute of Life Sciences, Ajinomoto, Inc., Kawasaki-shi, Japan.

Mariko Hirota is a Laboratory Technician in the Physiology and Nutrition Group at the Institute of Life Sciences, Ajinomoto, Inc., Kawasaki-shi, Japan.

Dr Julie A. Mennella is a member of the Monell Chemical Senses Center, Philadelphia, USA. Dr Julie A. Mennella is the corresponding author and can be contacted at: mennella@monell.org

To purchase reprints of this article please e-mail: reprints@emeraldinsight.com Or visit our web site for further details: www.emeraldinsight.com/reprints 


\section{This article has been cited by:}

1. Antonio Dario Troise, Alberto Fiore, Giovanni Roviello, Simona Maria Monti, Vincenzo Fogliano. 2014. Simultaneous quantification of amino acids and Amadori products in foods through ion-pairing liquid chromatography-high-resolution mass spectrometry. Amino Acids . [CrossRef]

2. Toshifumi Imada, Susan Shuzhen Hao, Kunio Torii, Eiichiro Kimura. 2014. Supplementing chicken broth with monosodium glutamate reduces energy intake from high fat and sweet snacks in middle-aged healthy women. Appetite 79, 158-165. [CrossRef]

3. A. K. Ventura, L. B. Inamdar, J. A. Mennella. 2014. Consistency in infants' behavioural signalling of satiation during bottle-feeding. Pediatric Obesity n/a-n/a. [CrossRef]

4. Yekta Dowlati, Arun V. Ravindran, Maxim Maheux, Meir Steiner, Donna E. Stewart, Jeffrey H. Meyer. 2014. No effect of oral tyrosine on total tyrosine levels in breast milk: implications for dietary supplementation in early postpartum. Archives of Women's Mental Health . [CrossRef]

5. J.A. Mennella, J.C. Trabulsi, L. Inamdar6. The sensory world of formula-fed infants: differences among artificial milk feedings in flavor learning and satiation 95-116. [CrossRef] 